\title{
The Persistence Of Traditional Gender Stereotypes: Evidence From The Distribution Of Academic Honors At A Female-Majority University
}

A. Lynn Phillips, Grove City College, USA

G. Michael Phillips, California State University, Northridge, USA

\begin{abstract}
A shift from male-majority to female-majority university campuses has opened up new areas for research on gender bias, stereotypes, and discrimination. At one large state university on the west coast, there were more female than male graduates in Spring, 2008 in 7 out of 8 colleges, including the traditionally male-majority areas of business and science. Relative probabilities for men and women of receiving honors in each major field of study at this school, compared to national data of gender breakdowns by field in 1980, showed that men and women were still relatively more likely to receive honors in fields that were traditionally male and female, respectively. Findings also cast doubt upon Kanter's tokenism hypothesis. Curiously, it was traditionally female, not male, fields that had the highest levels of gender inequity, though gender inequity overall may be on a decline. More research is needed to identify why this difference between gender and honors still exists. Universities should also be aware of the continuing potential for subtle gender discrimination, even in fields where equal numbers of men and women participate.
\end{abstract}

Keywords: student achievement, gender roles, discrimination, business school, academic honors

\section{INTRODUCTION}

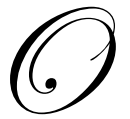

ver the past fifty years, the traditional college campus has undergone significant changes in demographics. One of these important shifts is from male-dominated student bodies to femaledominated student bodies. As Freeman documented, 56 percent of undergraduate students in 2004 were female, a significant increase from 1970, when they only composed 42 percent of the undergraduate student population (2004, p. 70). However, this raises an intriguing question: while many traditionally-male disciplines now find themselves to have mostly female students, have stereotypes regarding "female" and "male" occupations disappeared, or do they continue to manifest themselves in the university?

California State University Northridge (CSUN), which has always strived to maintain a tradition of accessibility and opportunity for its students, proved an ideal school at which to investigate this issue. After fifty years of providing undergraduate and graduate level education to students of varied backgrounds, CSUN is now one of the most diverse campuses in the United States of America. Currently, 56.5 percent of its student body is female, only 29.2 percent of its students are white (Office of Institutional Research, CSUN, 2009), and with the exception of the male-majority field of engineering, there were more female than male graduates in every area, including business and the sciences (Office of Student Development, CSUN, 2008). Because of this history and overall female-majority status, we thought that CSUN would likely be a leading example of egalitarianism in the United States. 
The idea of "male" versus "female" disciplines has manifested itself throughout history. Traditionally, "men specialize in and are primarily responsible for market work, and women specialize in and are primarily responsible for domestic work" (Reskin and Bielby, 2005, p. 73). This is found both in the labor force and in the university. Engineering and math, for instance, are traditionally male disciplines (Alexander and Thoits, 1985), while "nursing, librarianship, elementary school teaching, and social work" positions are generally filled by women (Williams, 1992, p. 253).

In the past, "skewed" groups such as these presented many challenges for the "tokens" of the non-common gender (Kanter, 1977). Women in traditionally-male fields, Kanter found, had to work harder than their male peers to receive recognition for their successes, while their failures were immediately known and commented upon. At least in part, this seems to hold true in the university: Rogers and Menaghan found that female undergraduates in male-dominated areas of study experience more "performance pressure" than their other female peers, though they are also more likely to persist in that major than are women in more balanced fields (1999). Men who take positions in female occupations, however, have not appeared to follow Kanter's tokenism model. Williams discovered in 1992 that male tokens are actually favored in female disciplines. In 2002, Budig suggested that men actually tend to be favored in any discipline, whether it is male-dominated, female-dominated, or balanced.

The current situation of largely female-majority classrooms leads to a new research opportunity. At CSUN, while engineering remains a strongly male-majority field, (a "skewed" area), the College of Business is now, in Kanter's terms, "balanced" (Kanter, 1977, p. 966). This phenomenon led to the opportunity to test Kanter's theory across two traditionally male fields, one of which still has "token" females, and one of which has approximately equal numbers of graduates of each gender.

In CSUN's other areas of study, female tokenism seems to have disappeared from this university, though biases and stereotypes regarding sex and occupation may still exist in fields associated with a particular gender. To both investigate this potential bias and test Kanter's theory, we analyzed data for graduating seniors from the Spring 2008 Honors Convocation and the Spring 2008 CSUN commencement to identify differences in rates of receiving honors for men and women within each college. We thought that this data would be likely to reveal gender biases still at work in the university, if any existed.

To test Kanter's theory of proportions with respect to academic honors, our first null hypothesis proposed that the relative distribution of honors by gender would be lower for females in a "skewed" rather than in a "balanced" environment, and thus that women would be relatively less likely to receive honors in CSUN's College of Engineering and Computer Science than in its College of Business.

Given that in all areas other than engineering at CSUN there are now more female than male graduates, a similar question of interest was how successful men and women are today in what were traditionally "male" and "female" disciplines. Has the university truly reached equality, or does it still treat students differently when they defy traditional gender roles? Assuming equal inherent ability in the population of men and women who select a particular major, our second null hypothesis proposed that equal percentages of males and females should receive honors, when one took into account the relative frequency of males and females in that major. If a major was 75 percent female, for instance, one would expect that 75 percent of that major's honors recipients would also be female.

We identified four other possible outcomes of this analysis, each with its own possible interpretation. First, it was possible that a higher relative percentage of females than males received honors in traditionally maledominated majors. If so, it would either suggest that females in a traditionally male-dominated major tend to outperform their male counterparts (perhaps due to a previous 'weeding out' process in high school or the early years of college, so that only female students with exceptional aptitude graduate in that major, while men might be encouraged to pursue "male" majors, no matter their actual aptitude for the subject), or that professors reward females in historically male-dominated majors disproportionately to their male students (perhaps wishing to encourage diversity or make up for perceived past discrimination against females). 
In contrast, it was possible that a lower relative percentage of females than males received honors in a traditionally male-dominated major. If this is correct, it would either suggest that females in traditionally-male majors tend to not shine academically (perhaps due to pressure associated with violating stereotypes, or a lack of preparation that their male counterparts received earlier in their academic careers), or that professors reward males in traditionally-male majors disproportionately to their female students (perhaps because they 'know' that males in these majors are better suited to that career than female students).

Similarly, it was possible that a higher relative percentage of females than males received honors in traditionally female-dominated majors. As above, if this was correct, it would suggest that males do not tend to succeed academically in these majors (again, perhaps due to pressure associated with violating stereotypes, or a lack of preparation that their female counterparts received earlier in their academic careers), or that professors reward females in traditionally female-dominated majors disproportionately to their male students (perhaps due to a feeling of resentment against men for trying to displace women from their traditional occupations, or a 'knowledge' that only men who failed elsewhere would want a 'woman's job').

Finally, it was possible that a lower relative percentage of females than males received honors in traditionally female-dominated majors. If this was the case, it would either suggest that males in a historically "female" major tend to outperform their female counterparts (perhaps because only those males who are exceptionally talented at that field choose a women-dominated major, while many females might choose that major for traditional reasons), or that professors reward males in these majors disproportionately to their female students (possible because they want to encourage diversity in their majors, or because they are impressed by the willingness of a man to enter a 'woman's field'). For any of these four outcomes, additional research would need to compare students' grade point averages and also take into account professor biases to determine which, if any, of these behavioral explanations is correct.

\section{METHODS}

Though there are many ways of comparing the likelihood of women receiving academic honors to that of men, many of them are problematic. A simple comparison of the number of women to the number of men receiving honors in a given major or college ignores the relative population sizes of women compared to men in that program. Similarly, a mere comparison of the percentage of honors given to women across different departments also ignores the population size and the relative percent of women in each department.

For this study, we computed and analyzed a ratio of the women's odds of honors to the men's odds of honors. This "relative odds ratio" was computed at the college level, using aggregated data from majors offered by 63 departments at CSUN. First, we found the ratio of females receiving honors to females not receiving honors, the "female honors ratio," for each available major. We also determined an analogous "male honors ratio" for each available major. In sum, we were able to thus compute 135 female honors ratios and 170 male honors ratios.

The discrepancy is due to numerous majors (and several departments) in which only females or only males had received honors that year. In such cases, while we could have computed the separate male and female honors ratios, the relative odds ratio would have involved a division by zero in those instances when no males received honors.

It would have been possible to eliminate the division of zero problem at the college level by taking the ratio of all females (or males) receiving honors across the college regardless of major to the number of all females (or males) graduating but not receiving honors. However, this would have introduced another difficulty. If there was disparate treatment in some majors versus others in a college, a majority of females (or males) might have chosen to go into specific majors that were more disposed to treat them favorably. If females (or males) in the "preferred" department received honors at roughly the same ratio as males (or females) in the "disparate" departments, such disparity would not be identified at the aggregated college level.

Consequently, we decided to use the expected values (arithmetic means) of the honors ratios within each college for the calculations. This female (or male) ratio was the expected honors ratio for a major chosen at random 
from the majors offered within the college. This was not a population weighted average, nor should it have been. Were the averages weighted by the number of females (or males) within each major, this would again allow results for the "preferred" major to mask potential disparity if there were other majors that had some bias against one of the genders. By using the major as the observational unit, unweighted by actual female (or male) enrollment, we were able to exclude any potentially confounding "favorable habitat" effects.

A relative odds ratio of approximately one for a college signified that its average female honors ratio was about the same as its average male honors ratio. Relative odds ratios of substantially below one indicated that a female in a randomly selected major within the college would have had a lower chance of receiving honors than would a male in the similarly randomly chosen major. Similarly, relative odds ratios substantially above one indicated that a female in a randomly chosen major within the college would have had a greater chance of receiving honors than would a similarly situated male student.

The U.S. Department of Education National Center for Education Statistics published data (henceforth, benchmark data) showing the number of males and females enrolled in broad subject areas, roughly corresponding to colleges, in 1980 (Peter, Horn, \& Carroll, 2005). For each of these areas, we computed the ratio of female students to male students. We then manually assigned each of these areas to the corresponding colleges at CSUN, and calculated the expected value of the female percentage for each college. The benchmark data did not cover most majors in the "College of Health and Human Development" (for example, the areas of recreation, kinesiology, and family and consumer science) so we could not compute a benchmark for that college. On the other hand, the area of Psychology was reported separately in the benchmark data and was the only "department level" data in the 1980 enrollment benchmarks. The reported benchmark data for Psychology showed a very different female enrollment percentage than for the aggregate of the rest of the College of Social and Behavioral Sciences (a 1980 national benchmark of 1.83 females to males in Psychology compared to .798 females to males for the other areas represented in the college). Consequently, we decided to treat Psychology separately from the remainder of the College of Social and Behavioral Sciences in this study.

For purposes of this paper, we defined areas in the 1980 benchmark data where the female to male ratio was below one as "historically male," and those where the ratio was above one as "historically female".

In addition to quantitative tests of these ratios, we also employed a more qualitative examination of the data. By comparing the difference between each department's 2008 relative odds ratio and its historical 1980 female-to-male ratio, we were able to see the degree of change in equality, if any, that had taken place in each area of study.

\section{ANALYSIS}

Table 1 shows the historical, and thus the expected, female to male ratios for each of the eight areas along with its designation of historical gender dominance. We did not find any of the areas to be approximately neutral.

Table 1: Categorization of 1980 Benchmark Data as Historically Male or Female

\begin{tabular}{|l|c|c|}
\hline \multicolumn{1}{|c|}{ Area of University } & $\begin{array}{c}\text { Benchmark: 1980 National } \\
\text { Female to Male Ratio }\end{array}$ & $\begin{array}{c}\text { Categorization of historically } \\
\text { female (f) or historically male } \\
(\mathbf{m})\end{array}$ \\
\hline Arts, Media, and Communications & 1.493 & $\mathrm{f}$ \\
\hline Business & 0.586 & $\mathrm{~m}$ \\
\hline Education & 2.970 & $\mathrm{f}$ \\
\hline Engineering and Computer Science & 0.168 & $\mathrm{~m}$ \\
\hline Humanities & 1.857 & $\mathrm{f}$ \\
\hline Psychology & 1.839 & $\mathrm{f}$ \\
\hline Science and Math & 0.615 & $\mathrm{~m}$ \\
\hline Social and Behavioral Sciences (excluding Psychology) & 0.798 & $\mathrm{~m}$ \\
\hline
\end{tabular}


After computing the benchmarks, we similarly categorized the relative odds ratios for each of the eight categories of 2008 CSUN data as favoring females, favoring males, or being neutral. We defined all ratios above 1.1 as favoring females, all below .9 as favoring males, and any in between .9 and 1.1 as being approximately neutral. The relative odds ratios and their categorization are presented in Table 2.

Table 2: Categorization of Female Honors Relative Odds Ratios from Northridge Spring 2008 Commencement Data

\begin{tabular}{|l|c|c|}
\hline \multicolumn{1}{|c|}{ Area of University } & $\begin{array}{c}\text { Female Honors Relative Odds } \\
\text { Ratios }\end{array}$ & $\begin{array}{c}\text { Categorization of relative odds } \\
\text { ratio as favoring females (f), } \\
\text { males (m), or being neutral (0) }\end{array}$ \\
\hline Arts, Media, and Communications & 1.307 & $\mathrm{f}$ \\
\hline Business & 0.850 & $\mathrm{~m}$ \\
\hline Education & 1.559 & $\mathrm{f}$ \\
\hline Engineering and Computer Science & 0.805 & $\mathrm{~m}$ \\
\hline Humanities & 1.699 & $\mathrm{f}$ \\
\hline Psychology & 1.145 & $\mathrm{f}$ \\
\hline Science and Math & 1.083 & 0 \\
\hline Social and Behavioral Sciences (excluding Psychology) & 1.860 & $\mathrm{f}$ \\
\hline
\end{tabular}

Using Kanter's theory as the basis of our first null hypothesis, we proposed that the relative odds of females receiving honors should be statistically smaller in the College of Engineering and Computer Science than in the College of Business. Conversely, a lack of statistical difference between these two colleges' data would lead to a rejection of the null. To test this hypothesis, we first calculated summary statistics for the majors-level data for both of these colleges. Seven of the offered engineering majors and 12 of the offered business majors had data for both male and female graduates. Using this information, we computed the female honors relative odds ratios for these 19 majors. From those ratios, we computed the standard error (standard deviation of the mean) for the average female honors relative odds ratios for both colleges. The results of these computations are presented in Table 3 .

Table 3: Data for testing Kanter's Hypothesis: Calculated from 2008 CSUN data

\begin{tabular}{|l|c|c|c|}
\hline \multicolumn{1}{|c|}{ Area of University } & $\begin{array}{c}\text { Number of } \\
\text { Majors in Study }\end{array}$ & $\begin{array}{c}\text { Average Female Honors Relative } \\
\text { Odds Ratio }\end{array}$ & $\begin{array}{c}\text { Standard Error of Relative Odds } \\
\text { Ratio }\end{array}$ \\
\hline Engineering & 7 & 0.805 & 0.211 \\
\hline Business & 12 & 0.850 & 0.256 \\
\hline
\end{tabular}

As shown, the average female honors relative odds ratio for the College of Engineering and Computer Science was well within one standard error of that for the College of Business. As such, there was clearly no statistically significant difference between the two areas $(\mathrm{p}=.432)$, so the null was strongly rejected. In this case, therefore, it appears that Kanter's theory was not accurate.

In our second set of tests, we show in Table 4 the gender dominance (historical categorization from benchmarks and categorization of relative odds ratios) for each academic area.

Table 4: Comparison of Gender Dominance: 1980 versus 2008

\begin{tabular}{|l|c|c|}
\hline \multicolumn{1}{|c|}{ Area of University } & $\begin{array}{c}\text { Categorization of historically } \\
\text { female (f) or historically male } \\
(\mathbf{m})\end{array}$ & $\begin{array}{c}\text { Categorization of relative } \\
\text { odds ratio as favoring females } \\
\text { (f), males (m), or being } \\
\text { neutral (0) }\end{array}$ \\
\hline Arts, Media, and Communications & $\mathrm{f}$ & $\mathrm{f}$ \\
\hline Business & $\mathrm{m}$ & $\mathrm{m}$ \\
\hline Education & $\mathrm{f}$ & $\mathrm{f}$ \\
\hline Engineering and Computer Science & $\mathrm{m}$ & $\mathrm{m}$ \\
\hline Humanities & $\mathrm{f}$ & $\mathrm{f}$ \\
\hline Psychology & $\mathrm{f}$ & $\mathrm{f}$ \\
\hline Science and Math & $\mathrm{m}$ & 0 \\
\hline Social and Behavioral Sciences (excluding Psychology) & $\mathrm{m}$ & $\mathrm{f}$ \\
\hline
\end{tabular}


To begin our statistical analysis, we employed a contingency table that compared the gender dominance distributions of the benchmark to the relative odds ratios for female honors, shown below (Table 5). Because of the small sample size, we used a Fisher-Freeman-Halton exact test. The null hypothesis for this test was that the data were randomly distributed and that there was no statistical impact of historical gender category and honors relative odds. The Fisher-Freeman-Halton test returned a p-value of .071, which led us to weakly reject the null hypothesis. It appeared that to some extent there was still a relation between being a traditionally "male" field and the probability of success in that field as measured by the honors relative odds ratio.

Table 5: A Contingency Table Test: 2008 Honors Relative Odds by 1980 Historical Gender Domination

\begin{tabular}{|l|l|c|c|c|}
\hline \multicolumn{2}{|c|}{} & \multicolumn{3}{c|}{ Honors Relative Odds Ratios } \\
\cline { 3 - 5 } \multicolumn{2}{|c|}{ Historically: } & Neutral & Female & Male \\
\cline { 2 - 5 } & female & 0 & 4 & 0 \\
\hline
\end{tabular}

We then performed a correlation analysis, comparing each area's benchmark female intensity to its female honors relative odds ratio. We computed its Spearman rank correlation rather than the common Pearson correlation because we had no specific reason to hypothesize that the magnitude of historical male enrollments in an area would directly correspond to the magnitude of males' relative odds of receiving honors. On the other hand, the Spearman rank would detect whether a more extreme male value in the benchmark corresponded to a more extreme relative odds of honors for males. The data for this test are shown in Table 6.

Table 6: Data for Spearman Correlation Analysis: 2008 Commencement Data compared with 1980 Benchmark Data

\begin{tabular}{|l|c|c|}
\hline \multicolumn{1}{|c|}{ College } & $\begin{array}{c}\text { Honors Relative } \\
\text { Odds Rank }\end{array}$ & $\begin{array}{c}\text { Historically Male } \\
\text { Benchmark Rank }\end{array}$ \\
\hline Arts, Media, and Communications & 5 & 5 \\
\hline Business & 2 & 2 \\
\hline Education & 6 & 8 \\
\hline Engineering and Computer Science & 1 & 1 \\
\hline Humanities & 7 & 7 \\
\hline Psychology & 4 & 3 \\
\hline Science and Math & 3 & 4 \\
\hline Social and Behavioral Sciences (excluding Psychology) & 8 & \\
\hline
\end{tabular}

Spearman Rank Correlation $=.714 \mathrm{p}=.025$

The Spearman rank correlation was computed to be .714. To determine whether this correlation was statistically meaningful, we performed a Fisher's correlation transformation, which resulted in a z-score of 1.946. This was weakly significant using a two-tailed standard normal approximation. As an alternative means of computing statistical significance, we ran a 10,000 trial Monte Carlo experiment in which the Spearman correlation between the historical gender rankings and randomized rankings was computed for each trial. Tabulating the Monte Carlo results identified that the original .714 Spearman correlation was equal to the two-tailed critical value but greatly exceeded the one-tailed critical value of .62. As the null hypothesis of no positive rank correlation between the historical benchmark value and the honors relative odds ratios was one-tailed, we were able to reject the null $(\mathrm{p}=.025)$.

A more qualitative look at the historical and contemporary data revealed additional information. As shown in Table 7, the 2008 relative odds ratio was closer to one than was the 1980 benchmark ratios in all cases but "Social and Behavioral Sciences." (This college was an anomaly: while in the benchmark data it was a male-dominated area of study, by 2008 it had reversed itself and actually had the highest level of inequity in terms of honors distribution, with a ratio of 1.86 in favor of women.) 
Table 7: A Comparison of Ratios; Computed from 1980 Benchmark Data and 2008 Commencement Data

\begin{tabular}{|l|c|c|c|}
\hline \multicolumn{1}{|c|}{ Area of University } & $\begin{array}{c}\text { Benchmark: 1980 } \\
\text { National Female to } \\
\text { Male Ratio }\end{array}$ & $\begin{array}{c}\text { CSUN Female } \\
\text { Honors Relative } \\
\text { Odds Ratio }\end{array}$ & $\begin{array}{c}\text { Difference } \\
\text { between ratios }\end{array}$ \\
\hline Engineering and Computer Science & 0.168 & 0.805 & 0.637 \\
\hline Business & 0.586 & 0.850 & 0.265 \\
\hline Science and Math & 0.615 & 1.083 & 0.468 \\
\hline Psychology & 1.839 & 1.145 & -0.694 \\
\hline Arts, Media, and Communications & 1.493 & 1.307 & -0.186 \\
\hline Education & 2.970 & 1.559 & -1.412 \\
\hline Humanities & 1.857 & 1.699 & -0.157 \\
\hline Social and Behavioral Sciences (excluding Psychology) & 0.798 & 1.860 & 1.062 \\
\hline
\end{tabular}

It is interesting to note that while most departments still leaned toward male or female dominance in terms of chances of getting honors, this difference was generally far less pronounced than it was for the 1980s benchmark data. By subtracting the CSUN relative odds ratio from the historical female to male ratio, we were able to identify a possible trend toward improvement in gender equity. This excludes the Social and Behavioral Sciences, which completely reversed their direction but actually increased their level of gender inequality. Aside from this anomaly, the area of psychology was the most different from the benchmark data overall, with an absolute difference in ratios of .694. This was followed closely by the still male-majority College of Engineering and Computer Science, which had a difference in ratios of .637. If CSUN in 1980 was accurately represented by these national benchmarks, these two colleges would have made the most progress towards gender equality since that time. It was also interesting to note that it was female-dominated, not male-dominated, departments in 2008 that had the highest levels of gender inequity in honors distribution. While male dominated areas have traditionally received condemnation for their poor treatment of women, it appears these areas have made significant progress towards equity in the past 20 years.

We calculated a simple measure of current gender inequity by subtracting the 2008 honors relative odds ratio from one, as a value of one represented equal relative odds of honors for men and women. According to the 2008 data, the most gender inequity found in a traditionally male-dominated area was .195 (1-.805, Engineering and Computer Science). While true that the most inequity in traditionally-male areas was found at the only college that is still male-dominated, it is interesting to note that four out of the five female-dominated areas showed more inequity than this in their distribution of honors (.307, Arts, Media, and Communications; .559, Education; .699, Humanities; .860 , Social and Behavioral Sciences).

\section{CONCLUSIONS}

As California State University at Northridge is a large state school that has focused on diversity and equity since its inception, the results of this study are likely generalizable to at least other schools of its type, and possibly also to other colleges across the United States. More research, however, should be done at small state schools, private schools, and colleges in different states to verify this study's findings.

At least at CSUN in 2008, gender differences were still present in various areas of the university, which by and large corresponded with the traditional gender patterns present in the 1980s. This is especially interesting given that in nearly every area, female graduates outnumbered male graduates according to the Spring 2008 data. These results cast doubt upon the generalizability of Williams' and Budig's findings: at least at this school, males were not favored in traditionally-female fields, as their research suggested should be the case. It is possible that these contradictory results are simply due to differences between academia and the job market, but more research must be done to determine the reasons for the opposite nature of these findings.

Additionally, Kanter's tokenism hypothesis failed to explain this school's data: female tokens in the College of Engineering and Computer Science were statistically no less likely to be awarded honors than were females in the balanced College of Business. This may be due to the work towards gender equity that has occurred over the past thirty years, as both the areas of business and engineering had far higher levels of female honors 
awarded than would have been predicted by the 1980 benchmark data. However, future research should explore the specific reasons that Kanter's hypothesis failed in this instance.

Future research should also investigate why a discrepancy between gender and reception of academic honors exists at all. As we used only specific data available from CSUN's Office of Student Development for this particular project, students' GPA, race, socio-economic status, and similar variables, were not able to be taken into account. Because of this, we assumed that males and females in the same major were identical in terms of their academic ability and desire to learn. Similarly, we did no research on the professors in any department, so we were not able to draw any conclusions about discriminatory attitudes or lack thereof at the university. At this point, therefore, it is unknown whether the discrepancy between honors reception at the school studied is on the student end or the faculty end.

Future research on this topic might investigate the correlation between gender and GPA in different areas of the university, and determine whether some majors are friendlier to women than to men or vice versa, and how that might relate to traditional gender-based stereotypes. Similarly, future studies might explore faculty attitudes towards their students of the non-stereotypical gender. Alternatively, it is possible that intrinsic differences between men and women are at least partly responsible for the success of particular sexes in particular fields of study. Future researchers might also take into account such variables as peer pressure, levels of familial encouragement, ethnicity, and religion when exploring this issue.

While even California State University, Northridge has apparently still not reached pure gender equality, it is encouraging to note that its level of gender equity today is far higher than that of the national benchmark data of the 1980s. Every traditionally male field of study at CSUN in 2008 was more equal in terms of treatment of women than would be predicted by the national benchmark data, (more than this, the Social and Behavioral Sciences at Northridge were found to be heavily female-dominated, as previously mentioned, though based on the national benchmark data this discipline was historically dominated by men). Similarly, areas that were historically female were also more equal at Northridge (though not by as much as its male disciplines) in terms of their treatment of the non-stereotypical gender than were the 1980s benchmark data. It is possible that as more and more students receive a broad education before college and are less limited by cultural stereotypes, this ratio will progress even more towards equality. Similarly, if the reason for different gender honors rates lies with professors' inherent biases, the situation should improve as new faculty are hired who were raised with weaker stereotypical images of acceptable male and female professions. Whichever is the case, universities across the country should be aware of the continuing potential for subtle gender discrimination against both women and men, so that appropriate policy decisions may be enacted.

\section{AUTHOR INFORMATION}

A.L. Phillips studied business, sociology, and research methods at Grove City College. She is currently working as a marketing research specialist for c4cast.com, Inc. Her ongoing research interests are primarily in cross-cultural consumer behavior. Her first publication, which explored differences between homeschooled students and nonhomeschooled students' choice of college major, is forthcoming in the fall 2010 edition of Sociological Viewpoints.

G. Michael Phillips is Professor of Finance at California State University, Northridge, where he specializes in online education. His research focuses on valuation in incomplete markets, macroeconomic impacts on financial markets, and advanced forecasting methods. He received his Ph.D. from the University of California, San Diego, in 1982. He was raised in central Illinois.

\section{REFERENCES}

1. Alexander, V. D., \& Thoits, P. A. (1985). Token Achievement: An Examination of Proportional Representation and Performance Outcomes. Social Forces, 64, 332-340.

2. Budig, M. J. (2002). Male Advantage and the Gender Composition of Jobs: Who Rides the Glass Escalator? Social Problems, 49, 258-277. 
3. Freeman, C. (2004). Trends in Educational Equity of Girls \& Women: 2004. Washington D.C.: U.S. Department of Education, National Center for Education Statistics.

4. Kanter, R. M. (1977). Some Effects of Proportions on Group Life: Skewed Sex Ratios and Responses to Token Women. The American Journal of Sociology, 82, 965-990.

5. Office of Institutional Research, CSUN. (2009, January 9). CSUN by the Numbers. Retrieved January 9, 2009, from CSUN.edu: http://www.csun.edu/ instrsch/csunnumbersindex.html

6. Office of Student Development, CSUN. (2008). Commencement Data, 2008. Northridge: Office of Student Development, CSUN.

7. Peter, K., Horn, L., \& Carroll, C. D. (2005). Gender Differences in Participation and Completion of Undergraduate Education and How They Have Changed Over Time. Washington, D.C.: National Center for Education Statistics.

8. Rogers, S. J., \& Menaghan, E. G. (1991). Women's Persistence in Undergraduate Majors: The Effects of Gender-Disproportionate Representation. Gender and Society, 5, 549-564.

9. Ruskin, B. F., \& Bielby, D. D. (2005). A Sociological Perspective on Gender and Career Outcomes. The Journal of Economic Perspectives, 19, 71-86.

10. Williams, C. L. (1992). The Glass Escalator: Hidden Advantages for Men in the "Female" Professions. Social Problems, 39, 253-267. 
NOTES 